\title{
The control system of the ecological hybrid two stages refrigerating cycle
}

\author{
Piotr Cyklis ${ }^{1, a}$ and Roman Duda ${ }^{1}$ \\ ${ }^{1}$ Poland, Cracow University of Technology, Department of Mechanical Engineering, Institute of Power and Process Engineering
}

\begin{abstract}
The compression anticlockwise cycle is mostly used for refrigeration. However due to the environmental regulations, the use of classic refrigerants: F-gases is limited by international agreements. Therefore the combined compression-adsorption hybrid cycle with natural liquids: water/carbon dioxide working as the energy carriers is a promising solution. This allows to utilize the solar or waste energy for the refrigeration purpose. In this paper application of the solar collectors as the energy source for the adsorption cycle, coupled with the low temperature (LT) refrigerating carbon dioxide compression cycle is shown. The control of the system is an essential issue to reduce the electric power consumption. The control of the solar heat supply and water sprayed cooling tower, for the adsorption cycle re-cooling, is presented in this paper. The designed control system and algorithm is related to the LT compression cycle, which operates according to the need of cold for the refrigeration chamber. The results of the laboratory investigations of the full system, showing the reduction of the energy consumption and maximum utilization of the solar heat for different control methods are presented.
\end{abstract}

\section{Introduction}

Compression and sorption systems are widely used in refrigeration and air conditioning systems for refrigeration and heat pumps cycles [2][3][4][5][6]. Restrictions for "F-gases" limits its application in such systems because of greenhouse and ozone depletion effect. The carbon dioxide cycle is commonly used refrigerant in the low temperature stage (LT) of the two stage compression refrigerating cycle. As a refrigerant in one stage refrigerating compression cycle only the transcritical cycle can be applied due to the low critical temperature of $\mathrm{CO}_{2}$. This requires high discharge pressure and high volume gas heat exchanger instead of the condenser. Coupling the adsorption cycle with water as working fluid as a high temperature stage (HT) and compression $\mathrm{CO}_{2}$ cycle, gives the possibility of standard Linde compression refrigeration cycle as LT stage with $\mathrm{CO}_{2}$ as natural refrigerant. This hybrid double stage cycle achieves higher COP than single stage cycle. Coupling this two systems: adsorption at the high temperature stage and $\mathrm{CO}_{2}$ compression at the low temperature stage is a new idea [1][2], allowing to utilize low temperature waste or solar heat as energy source for high temperature stage desorption.

The system with this level of complexity, where the required working time is continuous for the whole year operation, demands the optimisation of the automatic control of all subsystems and machines, to allow for automatic unwatched operation.

First requirement for the optimal control is to maintain all important measured parameters of the system within the required limits and react with proper system shutdown in unexpected cases. The system operation outside of the required limits may cause damage of the machines. Safety shutdown of a subsystem or individual machine with warning message for the service is required. The optimization part of the designed algorithms is to reduce the energy waste and minimize the power consumption.

The main purpose of this paper is to show the possibilities of the electric power consumption reduction using optimized control algorithm for chosen subsystems.

\section{The test stand}

In the Laboratory of Thermodynamics and Measurements of Thermal Machines at the Cracow University of Technology a test stand with hybrid refrigeration adsorption-compression system has been designed and constructed [2]. The HT stage is the adsorption cycle based actually (after upgrading) on the eCoo unit from German manufacturer (SorTech AG). This system is coupled with the tube solar collectors, the heat storage tank and the wet cooling tower for MT (medium temperature) glycol heat rejection system. The solar subsystem L4 contains 17 vacuum tube solar collectors HEWALEX KSR-10 and the heat storage tank of 20001 capacity. The evaporative (water sprayed) cooling tower DECSA REF-C-005, with maximum cooling power about $75 \mathrm{~kW}$ is used for the adsorption unit cooling. The low temperature compression cycle is equipped with the two $\mathrm{CO}_{2}$ compressors Dorin $\mathrm{CD} 300 \mathrm{H}$ ph3,

\footnotetext{
a Corresponding author: pcyklis@mech.pk.edu.pl
} 


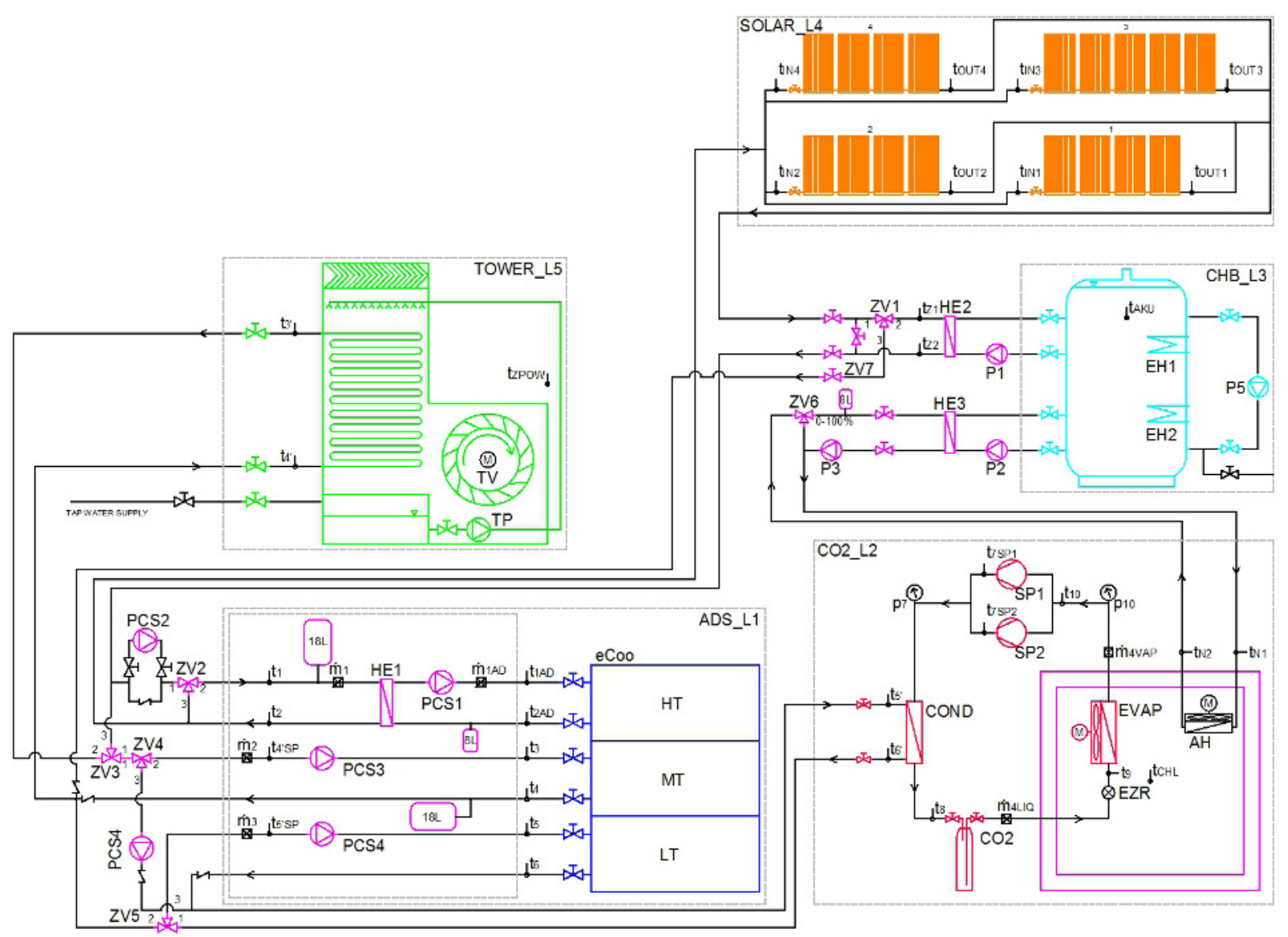

Figure 1. Schematic diagram of a complete hybrid refrigeration system installed in The Laboratory of Thermodynamics and Thermal Machines Measurements

working in the parallel cascade. One compressor is equipped with the frequency inverter ABB ACS355-0308A8-4. The refrigeration chamber has internal dimensions of $1960 \times 1920 \times 2690 \mathrm{~mm}$ and the wall insulation thickness of $200 \mathrm{~mm}$.

The chamber evaporator was delivered by Gunter CXGHF 040.2H/17-ENW50.E with the fan VT0398U and the high pressure expansion valve CX4. The lamellar heat exchanger SWEP B16DWHx64/1P-SC-U is applied as a $\mathrm{CO}_{2}$ condenser.

The ethylene glycol is used as a secondary liquid in the evaporative wet tower, the adsorption unit and solar subsystem. The air heater AH Flowair Leo FB9 was installed in the cooling chamber to simulate the thermal load. The scheme of the system is shown in figure 1.

The system has to work continuously with different load and weather conditions, so the wet cooling tower applied in our laboratory stand has more cooling capacity than required only for adsorption cooling. The adsorption cooling of the $\mathrm{CO}_{2}$ condenser is possible only in the period when the waste or solar heat is available. The heat container solar charging, allows only for a few hours operation, until the temperature drops below $55^{\circ} \mathrm{C}$, so only part time of the night operation of the adsorption cycle work may be powered from the storage tank. Then the cooling tower has to cool down the condenser directly. In case of extremely high air humidity, the electric heater may be used as a backup, which is not desirable due to the energy consumption and total COP decrease. The advantage of the adsorption system is, that it may work with $55-65^{\circ} \mathrm{C}$ desorption temperature source, depending on the adsorption unit design.

Several operation regimes for each subsystem were designed for system operation:

The subsystem L1 the adsorption unit - has four main regimes defined as:

1. A summer day operation (SDW): when the input temperature from the heat source exceeds $55^{\circ} \mathrm{C}$, and the ambient air temperature is higher than $13^{\circ} \mathrm{C}$. Then the adsorption subsystem works in the cooling mode. Since the outlet cooling temperature from the adsorption unit is a function of cooling load, it is sufficient to leave the cycle for lowest possible cooling temperature as possible. This self-adjustment function of the adsorption unit allows to achieve lowest possible condensing temperature, reducing total energy consumption. This regime works until two above mentioned temperatures used as control functions will not be exceeded.

2. A summer night operation (SNW): the adsorption unit operation is no longer possible when the heat source temperature decreases below $55^{\circ} \mathrm{C}$, then the adsorption 
system has to be switched off, and only the wet tower is used to cool down the $\mathrm{CO}_{2}$ condenser.

3. A heat pump operation (HPW): this option is used when the ambient air temperature decreases below $13^{\circ} \mathrm{C}$. Then the adsorption unit may be used separately as a heat pump collecting all waste heats and ambient heat and use the heat collector as HT source, while the MT (medium temperature heat) is used for heating.

4. An additional heater operation (AHW): The temperature of the heat source is below $60^{\circ} \mathrm{C}$ and the required condensing temperature cannot be obtained by the cooling tower. This may be the case only in special ambient conditions with high relative air humidity and high temperature when no waste or solar heat source is available.

The subsystem $\mathrm{L} 2-\mathrm{CO}_{2}$ compression cycle.

The basic function of the $\mathrm{CO}_{2}$ compression system is commonly known as compression-refrigeration cycle control, and will not be discussed here in details. However there are two important differences:

1. The cooling requirements for $\mathrm{CO}_{2}$ condenser may in some cases be limited, and additional cooling power will be required. In this case there are two possibilities: the control signal is released to run AHW program in the L1 subsystem, in the meanwhile reducing the compressor revolution speed.

2. The frequency inverter mounted on one of the cascade controlled compressors, allows for the variable refrigeration load control instead of the on/off control.

The subsystems L3,L4,L5 - heat container, solar collectors, wet cooling tower, have two or triple way valves and variable speed pumps to adjust temperatures and flow directions.

The solar pump PCS2 operational speed before andafter solar energy accumulation is controlled using the temperature in solar collectors as control parameter. Four below given equations are used for the control algorithm for the pump revolution speed. The optimal control of this pomp allows for power consumption decrease and the solar heat maximum utilization. Below given equations are related to:

(1) - the energy balance at the outflow from the solar collectors,

(2) - the energy balance at the inflow to the solar collectors,

(3) - the collectors temperature increase over the ambient temperature,

(4) - the temperature difference between the outflow and inflow to the solar collectors

$$
\begin{aligned}
& W_{1}=\log \left(\frac{\text { toUTkol_MAX }+273.15}{\text { toUTkol_AVG }+273.15}\right) \cdot C \\
& W_{2}=\log \left(\frac{\text { tINkol_MAX }+273.15_{\text {tINkol_AVG }}+273.15}{\text { IIV }_{1}}\right) \cdot D \\
& W_{3}=\log \left(\frac{\text { touTkol_MAX }-t_{\text {zpow }}+273.15}{t_{\text {zpow }}+273.15}\right) \cdot E
\end{aligned}
$$

$$
\begin{aligned}
& W_{4}=\log \left(\frac{\text { touTkol_MAX }_{-}+273.15}{t_{\text {INkol_AVG }}+273.15}\right) \cdot F \\
& O_{P C S 2}=A \cdot\left(W_{1}+W_{2}+W_{3}+W_{4}\right)+B
\end{aligned}
$$

where:

A - the set point of the maximum rotational speed of the pump,

tOUTkol MAX - the temperature maximum value at the solar collector outflow,

$$
\text { touTkol_maX }=\max (\text { tout1, tout2, touT3, tout4 })
$$

tOUTkol_AVG - the average temperature value at the solar collector outflow,

$$
\text { toUTkol } \_ \text {} A V G=\frac{\text { touT } 1+\text { touT2 } 2+\text { touT3 } 3+\text { touT } 4}{4}
$$

the same form of equations are used for calculations of inflow temperatures $t_{I N k o l} M A X$ and $t_{I N k o l} A V G, t_{\text {zpow }}$ is the external ambient temperature,

$\mathrm{B}=1000, \mathrm{C}=5, \mathrm{D}=10, \mathrm{E}=2,5, \mathrm{~F}=3,5$ are coefficients experimentally adjusted after tests testing.

If the average temperature of the outflow from the solar collectors increases above the temperature in the heat container, the solar energy accumulation starts:

$$
\text { toUTkol_AVG }>=t_{A K U}+\text { hysteresis PID }
$$

Then when the touTkol $A V G$ decreases below $t_{A K U}+0,5 \cdot$ hysteresisPID the PID controller is switched off and equations (1)-(5) are used for control.

$$
\text { tOUTkol_AVG }_{\text {S }}<=t_{A K U}+0.5 \cdot \text { hysteresisPID }
$$

The hysteresis added in the equation 8 and 9 was observed during experiments. In this case the it is value of $8 \mathrm{~K}$.

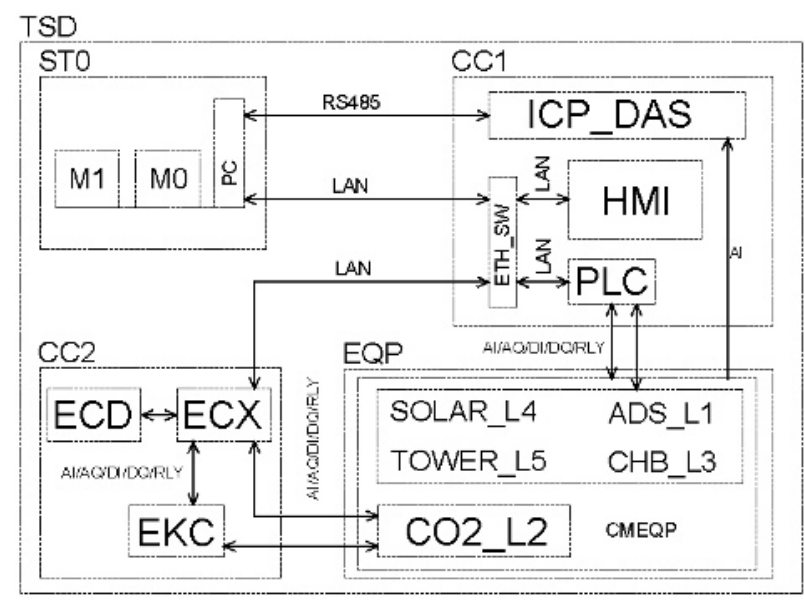

Figure 2. Schematic block diagram of the control system. 

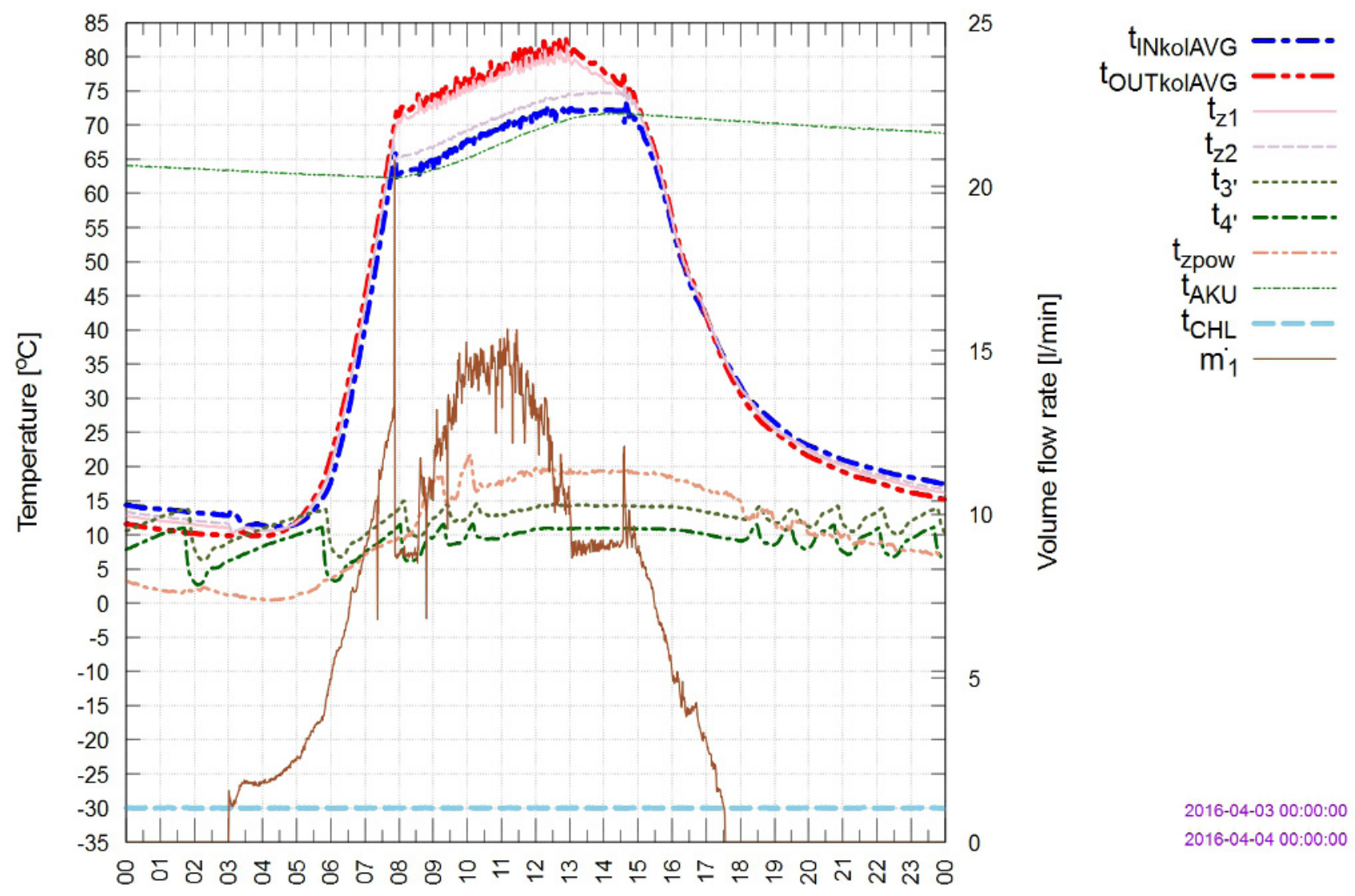

Time [hour]

Figure 3. Temperature distributions $\mathrm{SOLAR}+\mathrm{CO} 2+\mathrm{TOWER}, \mathrm{t}_{\mathrm{INkolAVG}}$ - the temperature averaged value at the solar collector inflow, $\mathrm{t}_{\mathrm{OUTkolAVG}}$ - the temperature averaged value at the solar collector outflow, all other parameters notations are shown in Fig. 1.

When the temperature " $t_{A K U}+$ hysteresisPID" is reached the P1 pump and PCS2_PID controller is switched on and accumulation starts.

During the night time the pump is switched off.

The heat container subsystem is simple in operation. It has electric heaters EH1 and EH2 with on/off system only for L1 AHW mode. The valves ZV and pumps have to work accordingly to other subsystem modes.

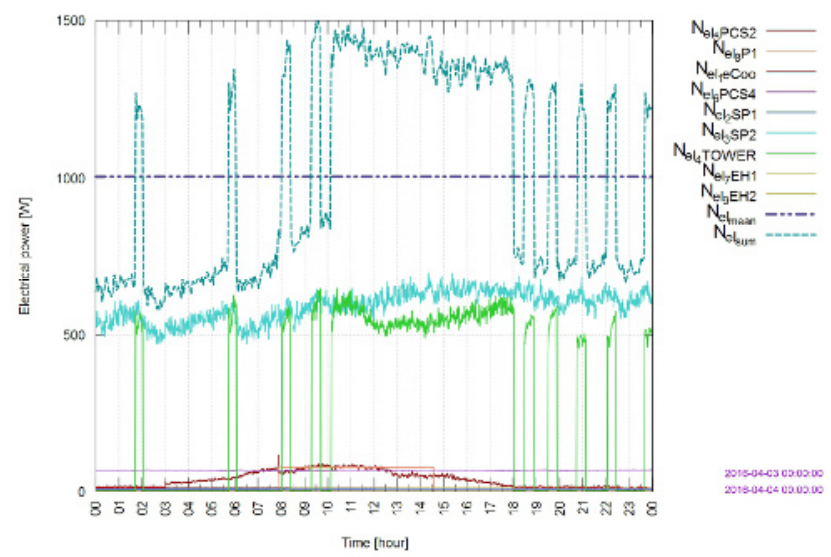

Figure 4. Electrical power consumption of the system SOLAR+CO2+TOWER, $\mathrm{Ne}_{\text {mean }}$ - power consumption averaged during the operation period, $\mathrm{Nel}_{\text {sum }}$ - summary power consumption during the operation period, all other parameters notations are shown in fig 1
1. Mode SAC - the solar heat accumulation is controlled using the temperature difference $\mathrm{tz}_{1}-\mathrm{tz}_{2}$ with the control set point $4 \mathrm{~K}$. This set point adjusts the PCS2 pump speed through the PID controller. In the case of the full heat container load $\left(95^{\circ} \mathrm{C}\right)$ the mode SAC is changing into the mode SWS.

2. The mode SW (solar operation)- the heat accumulator is fully loaded $\left(95^{\circ} \mathrm{C}\right)$, then $\mathrm{P} 1$ pump is switched off. If the L1 subsystem is on the SDW mode the glycol is directly heating the adsorption unit. In the case of the too high solar temperature, the subsystem L1 is switched off, or the mode SW change into SWS mode.

3. The SWS mode - the solar waste mode. This is the case when no heat source is needed (L1 is not operating, accumulator is full) and there is a considerable amount of solar radiation and the temperature readings in solar subsystem exceeds the set points (about $100^{\circ} \mathrm{C}$ ) then pump PCS2 has to be switched on and all heat is lost in the cooling tower.

The measurement system operates with the designed in the Laboratory under Visual Studio software „kaskada”. Part of this software called kaskada_vi was written using the Lab View. The NIST REFPROP software for refrigerant properties was implemented. The CoolPack and Mathcad software for data calculations were used. The values of the 36 temperatures, 6 flow 
rates, 5 gauge pressures, 9 electric power meters are recorded each minute. Schematic block of the system with measurement system is shown in figure 2 .

An example of the temperature distributions in the system during one operating day is presented in figure 3 .

This data is used for calculations and simultaneously send to the main plc SIEMENS S7 $1217 \mathrm{C}$ unit.

The SIEMENS S7 unit controls the system programmed using SIEMENS TIA Portal software.

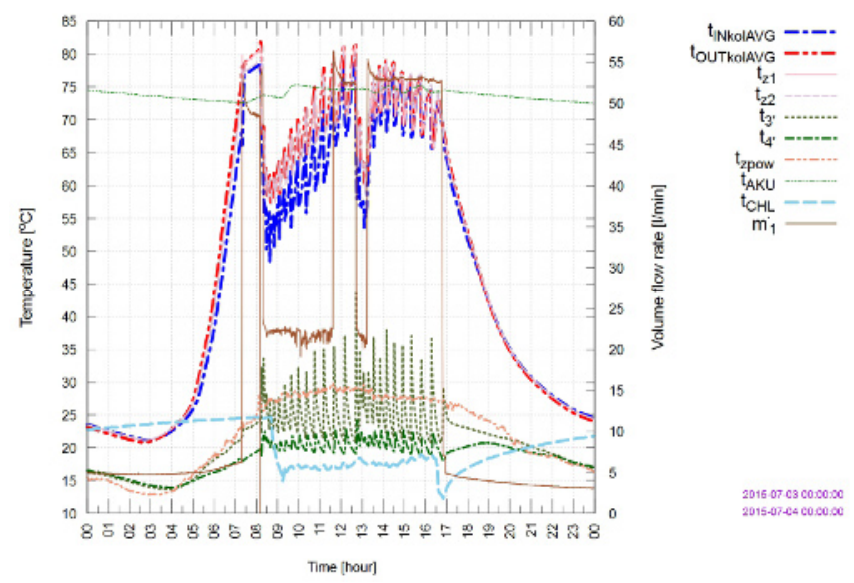

Figure 5. Temperature distributions $\mathrm{SOLAR}+\mathrm{CO} 2+\mathrm{ADS}$, $\mathrm{t}_{\text {INkolAVG }}$ - the temperature averaged value at the solar collector inflow, $t_{\text {OUTkolAVG }}$ - the temperature averaged value at the solar collector outflow, all other parameters notations are shown in fig. 1

\section{The control system}

In figure 2 the schematic diagram of the control system is presented with the following depicted elements:

CC1 MAIN CASE - measurements of: temperature and pressure, mass and volume flow rates, electric power for electric devices, depicted in figure 1. Also PLC controller for the whole system is included.

The main parts are:

- ICP DAS 8 pcs. M-7017RC cards, for data acquisition, this as a whole measuring system gives 64 analogue inputs signals of which 52 are used at this development stage.

- PLC SIEMENS S7 CPU 1217C controller with Ethernet/PROFINET interface and CM 1241 RS485 - HMI KTP700 Basic PN operator panel with Ethernet/PROFINET interface for communication.

- EQP subsystems of the refrigeration stand,

- $\mathrm{CO} 2$ L2 2 compression system $\mathrm{CO}_{2}$,

- SOLAR_L4 solar subsystem,

- CHB L $\overline{3}$ heat container,

- ADS L1 adsorption unit,

- TOWER_L5 water sprayed cooling tower,

- CMEQP common part of the acting elements: servomotors for valves, circulating pumps,

- ETH SW network switch LAN 1000/100/10 Mbit/s,

C $\bar{C} 2$ subsystem CO2 CASE - consists of independent controller EKC with independent safety subsystem, overheating controller for expansion valve ECX, this controller has a build in www page where operating
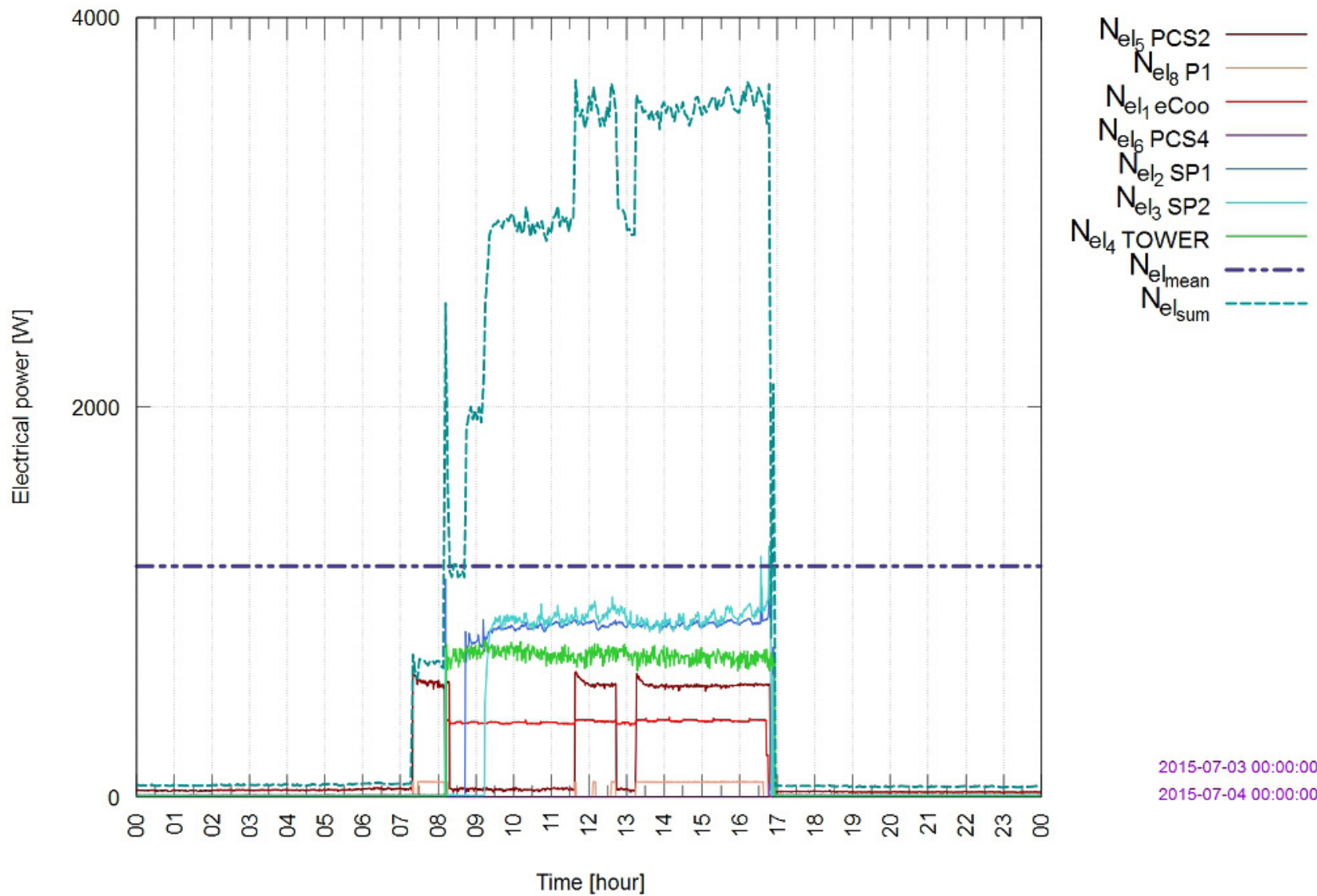

Figure 6. Electrical power consumption of the system SOLAR+CO2+ADS, $\mathrm{Ne}_{\text {mean }}$ - power consumption averaged during the operation period, $\mathrm{Nel}_{\text {sum }}$ - summary power consumption during the operation period, all other parameters notations are shown in fig. 1 
parameters can be changed remotely using web page browser, ECD controller parameters display.

\section{Tests results}

The selected day of the system work with the solar energy accumulation and $\mathrm{CO}_{2}$ condenser cooled directly from evaporative cooling tower is presented in figure 3 (temperatures) and figure 4 (power consumption).

The selected day of the system operation with adsorption unit switched on is presented in figure 5 (temperatures) and fig. 6 (power consumption). The power reduction and savings using the control system is clearly visible as Nelmean.

This value represents electric power consumption averaged during the operation period. If no optimised control would be introduced, the electric power consumption would be the maximum value of $\mathrm{Nel}_{\text {sum }}$ for all the operation time, which is considerably higher.

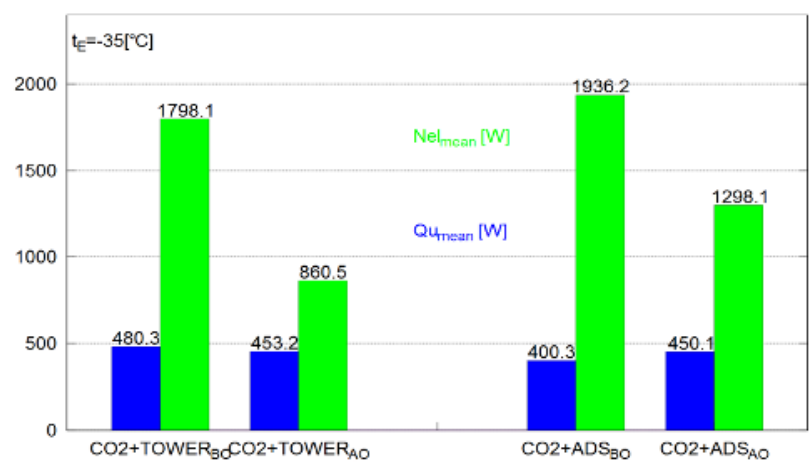

Figure 7. Electric power consumption and heat transferred from $\mathrm{CO}_{2}$ evaporator EVAP. $\mathrm{BO}$ - before optimization; $\mathrm{AO}-$ after optimization, $\mathrm{t}_{\mathrm{E}}-\mathrm{CO}_{2}$ evaporation temperature, all other parameters notations are shown in fig. 1

Summary of the results is shown in figure 7 . It is worth noticing that in all cases the electric power consumption was several times lower than before the optimisation.

\section{Conclusions}

The hybrid system worked out in the Laboratory of Thermodynamics and Thermal Machines Measurements combines the ecology of the natural refrigerant with high efficiency of the refrigeration system. To achieve this task the control system with specially designed algorithm was implemented. The control system contains frequency inverters for the pumps and compressor revolution speed. The control parameters are measured every 10 seconds and are recorded for future analysis. Parallel the control system adjusts the frequency inverters to achieve desired flows. The main assumptions for control system the algorithm design were the minimisation of the electric power consumption with the maximisation of the solar heat usage. This requires the frequency inverter controls for pumps, to keep the solar liquid flow on the level which allows for the heat container loading, even in low sun radiation condition. The algorithm is designed for the whole year operation. Selected results are shown in this paper. The uncontrolled system without control optimisation has in some cases twice the power consumption than after the control optimisation algorithm application. This increases the COP of the system, making this system more economically efficient. The results of the control algorithm operation are shown in the paper.

\section{References}

1. P. Cyklis, G. Brak, Trans. IFFM, 121, 49-66, (2008)

2. P. Cyklis, INT J REFRIG, Vol. 48, s. 121-131, (2014)

3. P. Cyklis, K. Janisz, Chem. and Proc. Eng., Vol. 36, No. 3, s. 321-330, (2015)

4. A. Grzebielec, AoT, 30, 189-200, (2009)

5. W. Han, L. Sun, D. Zheng, H. Jin, S. Ma, X. Jing, Applied Energy, 106, 383-390, (2013)

6. Suamir I., Tassou S. Appl. Therm. Eng., 50, 14871495, (2013) 